\title{
PENGARUH TERAPI RELAKSASI PERNAFASAN DALAM TERHADAP PENURUNAN KECEMASAN ANAK SD KELAS 6 DALAM MENUNGGU HASIL UJIAN NASIONAL (UAN) DI SDN-4 KUMPAI BATU BAWAH
}

\author{
Jelly Renaldy ${ }^{1}$ Dr M. Zainul Arifin ${ }^{2}$ Christina T. Setiawan ${ }^{3}$ \\ ${ }^{123}$ STIKes Borneo Cendekia Medika Pangkalan Bun \\ 1email : jellyrenaldy@gmail.com, 2email : M.zainularif17@gmail.com, 3email : \\ csetiawan.366@gmail.com
}

\begin{abstract}
ABSTRAK
Pendahuluan: Siswa merupakan pelajar yang duduk dimeja belajar yang menuntut ilmu dalam pendidikan. Dalam istilah siswa merupakan peserta didik dan jenjang pendidikan menengah pertama dan menengah keatas. Siswa dapat ditinjau dari berbagai pendekatan misalnya, pendekatan psikologis, pendekatan sosial, dan pendekatan edukatif. Ketenangan dalam menunggu hasil ujian nasional mutlak diperlukan bagi peserta siswa. Beberapa upaya yang dapat dilakukan untuk mengurangi kecemasan yang berlebihan dengan terapi music, dengan liburan ketempat yang menarik, salah satunya dengan cara melakukan terapi relaksasi nafas dalam. Relaksasi nafas dalam adalah bagaimana menghembuskan nafas secara perlahan, selain bisa mengurangi kecemasan, bisa juga menurukan intensitas nyeri. Teknik relaksasi nafas dalam dapat juga meningkatkan ventilasi paru dan meningkatkan oksigenasi darah. Tujuan penelitian ini adalah menganalisis pengaruh terhadap kecemasan sebelum dan sesudah diberikan terapi relaksasi pada anak SD. Bahan dan metode penelitian: Desain penelitian yang digunakan adalah pra eksperimen dengan pendekatan one group pre test post tets, variabel independende terapi relaksasi pernapasan dalam dan variable dependen Penurunan kecemasan. Populasi Semua anak SD kelas 6 yang sedang menunggu hasil ujian di SDN-4 kumpai batu bawah yang berjumlah 20 orang dan besar sample seluruh anak SD kelas 6 yang sedang menunggu hasil ujian di SDN-4 kumpai batu bawah yang berjumlah 20 orang.Teknik sample Total sampling. Pengumpulan data dengan lembar observasi. Pengolahan data editing, coding, tabulating, scoring dengan Uji Wilcoxon. Hasil penenelilitan: Hasil penelitian Terapi relaksasi pernapasan dalam sebelum diberikan terapi semua cemas sebanyak 20 responden $(100 \%)$ dan sesudah setelah diberikan terapi relaksasi pernafasan dalam tidak cemas sebanyak 17 responden $(85 \%)$ dengan nilai $\mathrm{p}$-value $0,000<0,05$ yang artinya $\mathrm{H} 1$ di terima. . Kesimpulan: Dalam penelitian ini peneliti dapat menyimpulkan ada pengaruh terapi relaksasi pernafasan dalam terhadap penurunan kecemasan anak sd kelas 6 dalam menunggu hasil ujian nasional (uan) di sdn-4 kumpai batu bawah.
\end{abstract}

Kata kunci: Anak SD, kecemasan, Terapi relaksasi pernafasan dalam

\author{
EFFECT OF RELAXATION THERAPY BEHAVIOR IN AGAINST \\ DECREASE OF ANIMAL CHILDREN CLASS 6 CLASS IN WAITING THE \\ NATIONAL TEST RESULT (UAN) IN SDN-4 KUMPAI BATU BAWAH
}

\section{ABSTRACT}


Preliminary : Students are students who sit at the desk of study that is studying in education. In terms of students are students and junior secondary and upper secondary education. Students can be viewed from various approaches eg, psychological approach, social approach, and educative approach.Quietness in waiting for national exam results is absolutely necessary for student participants. Some efforts can be made to reduce excessive anxiety with music therapy, with a vacation to a place of interest, one of them by way of deep breathing relaxation therapy. Deep breath relaxation is how to breathe slowly, in addition to reducing anxiety, can also decrease the intensity of pain. Deep breath relaxation techniques can also improve lung ventilation and increase blood oxygenation.

The purpose of this study was to analyze the effect on anxiety before and after relaxation therapy in elementary school children. Research methods : The research design used was pre experiment with one group pre post test tets approach, independend variable of deep breathing relaxation therapy and dependent variable decreased anxiety. Population All sixth graders who are awaiting test results at SDN-4 bottom rock cohesion totaling 20 people and a large sample of all 6th grade elementary students who are awaiting test results in SDN-4 bottom rock cohesion totaling 20 people. Total sample technique Sampling. Data collection with observation sheet. Data processing editing, coding, tabulating, scoring with Wilcoxon Results and discussion : Test. The result of the study of respiratory deep relaxation therapy before giving all the anxious treatment as much as 20 respondents (100\%) and after after breathing relaxation therapy in not worry as much as 17 respondents (85\%) with p-value $0.000<0,05$ which means $H 1$ received. Conclusion: The conclusion of this research is the effect of deep breathing relaxation therapy on the decreasing anxiety of children up to grade 6 in waiting for national exam results (uan) in sdn-4 lower stone cohorts.

Keywords: elementary school children, Anxiety, Deep relaxation breathing therapy.

\section{PENDAHULUAN}

Ujian nasional merupakan sesuatu yang diwajibkan bagi para siswa-siswi sebagai persyaratan kelulusan. Hasil ujian dapat dijadikan bukti kesanggupan bagi para siswa berpikir secara logis melalui proses yang memenuhi standar kompetensi yang ditentukan dan sesuai dengan prosuder akademik. Bukan sebagai bahan pertimbangan kelulusan. Menurut Sarwono, 2007, didalam Hisam, (2016, 14) Siswa merupakan setiap orang yang secara resmi terdaftar untuk mengikuti pelajaran di duniapendidikan.

Jumlah orang menderita gangguan kecemasan baik akut maupun kronik mencapai $5 \%$ dari jumlah penduduk disuatu negara, dengan perbandingan antara wanita dan pria adalah dua dibanding satu, dan diperkirakan antara $2 \%$ sampai $4 \%$ diantara penduduk suatu saat dalam kehidupannya pernah mengalami gangguan kecemasan (Hawari, 2011, 34 ). Didapatkan hasil penelitian yaitu siswa kelas XII yang akan mengikuti UAN diperoleh tingkat kecemasan sedang dengan 60,4\%, 
tingkat kecemasan rendah $35,4 \%$ dan untuk tingkat kecemasan tinggi di peroleh 4,2 \% dengan sampel 404 siswa.

Berdasarkan penjelasan diatas, maka peneliti ingin membuktikan apakah ada pengaruh terapi relaksasi pernafasan dalam terhadap penurunan kecemasan anak sd kelas 6 dalam menunggu hasil ujian nasional (uan) di sdn-4 kumpai batu bawah.

\section{METODE PENELITIAN}

Penelitia ini bertujuan untuk menganalisis pengaruh terhadap kecemasan sebelum dan sesudah diberikan terapi relaksasi pada anak SD. Penelitian ini menggunakan desain pra eksperimen dengan motode one group pre test post tets cara dilakukan pre test terlebih dahulu sebelum diberikan intervensi kemudian setelah diberi intervensi dilakukan post test (Hidayat \& Alimun, 2010, 67).

Populasi Semua anak SD kelas 6 yang sedang menunggu hasil ujian di SDN-4 kumpai batu bawah yang berjumlah 20 orang dan besar sample seluruh anak SD kelas 6 yang sedang menunggu hasil ujian di SDN-4 kumpai batu bawah yang berjumlah 20 orang.

Pengambilan sampel dalam penelitian ini menggunakan metode Teknik sample Total sampling. Total sampling adalah teknik pengambilan sampel dimana jumlah sampel sama dengan populasi (Sugiyono, 2007, 70).

Variabel bebas dalam penelitian ini ialah Terapi relaksasi pernapasan dalam. Yang didefinisikan Suatu tindakan untuk mengurangi tingkat kecemasan dengan cara pernapasan dalam. Variabel indevenden dalam penelitian ini ialah Penurunan kecemasan yang di definisikan Penurunan Perasaan takut dan kehilangan kepercayaan diri pada kecemasan

instrumen penelitian ini ialah lembar observasi. Lembar observasi terdiri dari 2 bagian yaitu sebelum dan sesudah diberikan terapi. yang terdiri dari 37 pertanyaan. Menurut Arikunto (2006:1630) metode penelitian merupakan cara yang dugunakn oleh peneliti dalam mengumpulkan data untuk penelitian,, sedangkan instrument penelitian adalah alat yang digunakan untuk mengumpulkan data, supaya hasilnya lebih baik, dalam arti lebih cermat,lengkap, dan sistematis sehinggalebih mudah diolah.

Teknik analisa bivariat yang digunakan peneliti dalam penelitian ini untuk mengetahui seberapa besar pengaruh terapi relaksasi pernafasan dalam terhadap penurunan kecemasan peneliti menggunakan uji Wilcoxon dengan bantuan software SPSS.

\section{HASIL PENELITIAN}

\section{Data Umum}

Tabel 5.1 Distribusi frekuensi responden berdasarkan jenis kelamin

\begin{tabular}{cccc}
\hline No & $\begin{array}{c}\text { Jenis } \\
\text { kelamin }\end{array}$ & Jumlah & $\begin{array}{c}\text { Persentase } \\
(\%)\end{array}$ \\
\hline 1 & Laki-laki & 12 & $60 \%$ \\
\hline 2 & Perempuan & 8 & $40 \%$ \\
\hline & & & \\
\hline & Total & 20 & $100 \%$ \\
\hline
\end{tabular}

Sumber Data: Primer 
Berdasarkan tabel 5.1 menunjukan sebagian besar dari responden berjenis kelamin laki-laki berjumlah 12 orang $(60 \%)$.

\section{Data Khusus}

Tabel 5.2 Distribusi Responden Berdasarkan kecemasan siswa-siswi SDN 4 Kumpai Batu Bawah tahun 2017.

\begin{tabular}{|l|l|c|c|}
\hline No & Katagori & Jumlah & $\begin{array}{c}\text { Persentase } \\
(\%)\end{array}$ \\
\hline 1 & $\begin{array}{l}\text { Tidak } \\
\text { Cemas }\end{array}$ & 0 & $0 \%$ \\
\hline 2 & Cemas & 20 & $100 \%$ \\
\hline & Total & 20 & $100 \%$ \\
\hline
\end{tabular}

Sumber Data: Primer

Berdasarkan tabel 5.2sebelum diberikan terapi relaksasi pernafasan dalamdiketahui seluruhnya respondenmengalami kecemasanyaitu sebanyak20 orang (100\%).

Tabel 5.3 Distribusi Responden Berdasarkan kecemasan pada siswasiswi SDN-4 Kumpai Batu Bawah Sumber Data: Primer

Berdasrkan tabel 5.3 sesudah diberikan terapi pernafasan diketahuihampir seluruhnya responden tidak mengalami kecemasan yaitu sebanyak 17 orang $(85 \%)$.

Tabel 5.4 Distribusikecemasan karena pemberian terapi relaksasi pernafasan dalam table berikut :

\begin{tabular}{|l|l|l|l|l|}
\hline \multirow{2}{*}{ Katagori } & \multicolumn{4}{|l|}{ Wilcoxon Signed Rank Test } \\
\cline { 2 - 5 } & \multicolumn{4}{|l|}{$\begin{array}{l}\text { Perlakuan (terapi relaksasi } \\
\text { pernafasan dalam) }\end{array}$} \\
\cline { 2 - 5 } & Sebelum & $\begin{array}{l}\text { Pro } \\
\text { sent } \\
\text { ase }\end{array}$ & $\begin{array}{l}\text { Se } \\
\text { su } \\
\text { da } \\
\text { h }\end{array}$ & $\begin{array}{l}\text { Pro } \\
\text { sen } \\
\text { tase }\end{array}$ \\
\hline $\begin{array}{l}\text { Tidak } \\
\text { cemas } \\
\text { Cemas }\end{array}$ & 0 & $0 \%$ & 17 & $\begin{array}{l}85 \\
\%\end{array}$ \\
& 20 & 100 & 3 & $\begin{array}{l}15 \\
\%\end{array}$ \\
\hline $\begin{array}{l}\text { Hasiluji } \\
\text { wilcoxon }\end{array}$ & 9.00 & \multicolumn{4}{|l}{153.00} \\
\cline { 2 - 6 } & $P=.000$ & & \multicolumn{3}{|l}{} \\
\hline
\end{tabular}

Sumber: Data Primer

Berdasarkan tabel 5.4 menunjukan bahwasebagian besar responden sebelum diberikanterapirelaksasi pernafasan dalam mengalami kecemasan sebanyak 20 responden (100\%) dan setelah diberikan terapi relaksasi pernafasan dalam tidak cemas sebanyak 17 responden (85\%).kecemasan anak SD kelas 6 dalam menunggu hasil ujian nasional (UAN) di SDN-4 Kumpai Batu Bawah.

\section{PEMBAHASAN}

\begin{tabular}{|l|l|c|c|}
\hline No & Katagori & Jumlah & $\begin{array}{c}\text { Persentase } \\
(\%)\end{array}$ \\
\hline 1 & $\begin{array}{l}\text { Tidak } \\
\text { cemas }\end{array}$ & 17 & $85 \%$ \\
\hline 2 & Cemas & 3 & $15 \%$ \\
\hline & Total & 20 & $100 \%$ \\
\hline
\end{tabular}

\section{Kecemasan sebelum diberikan terapi} relaksasi pernafasan dalam

Berdasarkan tabel 5.2 didapatkan hasil sebagian besar sebelum diberikan terapi relaksasi pernafasan dalam,seluruhnya responden mengalami kecemasan sebanyak 20 responden $(100 \%)$. 
Menurut peneliti seseorang akan mengalami Cemas dalam melewati proses yang dilewati selama duduk di bangku sekolah, salah satunya yaitu ujian nasional yang kebanyakan dianggap siswa hal yang menakutkan bagi meraka. Ketika mereka telah melewati ujian nasional kecemasan yang dialami masih ada karena mereka masih menunggu hasil dari ujian nasioanl tersebut. Hasil ujian dapat dijadikan bukti kesanggupan bagi parasiswa berpikir secaralogis melalui proses yang memenuhi standar kompetensi yang ditentukan dan sesuai dengan prosuder.

Beberapa upaya yang dapat dilakukan untuk mengurangi kecemasan yang berlebihan dengan terapi music, dengan liburan ketempat yang menarik, salah satunya dengan cara melakukan terapi relaksasi nafas dalam.

Kecemasan adalah respon individu terhadap suatu keadaan yang tidak menyenangkan dan dialami oleh semua makhluk hidup dalam kehidupan sehari-hari (Suliswati, 2005, 71). individu dengan individu yang lain mempunyai kecemasan yang berbedabeda khusunya antara laki-laki dan perempuan. Laki-laki lebih cenderung mempunyai kecemasan yang lebih dibanding dengan perempuan. Hal ini dibuktikan oleh teori (Taylor \& Le Mone, 1997, 12 ). Perempuan lebih suka mengkomunikasikan rasa cemasnya, sedangkan laki-laki lebih sering menyembunyikan perasaan cemasnya dan berusaha terlihat lebih tegar dihadapan keluarganya.

Dari pernyataan di atas menunjukan adanya keserasian antara teori dan kenyataan yang ada pada responden. Hal ini disebabkan responden tersebut belum mengetahui cara penatalaksanaan mengurangi kecemasan Mereka juga belum mengetahui kalau kecemasan dapat diatasi dengan cara yang aman tanpa mengganggu kesehatan tubuh yang lain yaitu terapi relaksasi pernafasan dalam terhadap penurunan kecemasan.

\section{Kecemasan sesudah diberikan terapi relaksasi pernafasan dalam}

Tabel 5.3 menunjukan hampir dari keseluruhan responden tidak mengalami kecemasan sebanyak 17 responden $(85 \%)$.

Slmeltzer dan bare, 2002 di dalam Prasetyo, 2012, 72) tekni relaksasi nafas dalam adalah untuk meningkatkan ventilasi alveoli, memelihara pertukaran gas, mencegah atelektasi paru, meningkatkan efisiensi batuk mengurangi stess baik stess fisik maupun emosional yaitu menurunkan intensitas nyeri dan menurukan kecemasan.

Kecemasan pada siswa-siswi berkurang karena diberikan terapi relaksasi nafas dalam dan keinginan kuat siswa-siswi untuk mengatahui cara mengurangi kecemasan.

\section{Hasil Uji Statistik}

Hasil pengujian stastikti dengan menggunakan uji Wilcoxson Signed Rank Tes dengan tingkat kemaknaan $\alpha$ $<0,05$ didapat hasil $\mathrm{p}$ value $=0,000$ karena nilai sig.(2-tailed) $0,000<$ 0,05maka Ho ditolak dan H1 diterima, maka ada pengaruh terapi relaksasi pernafasan dalam terhadap penurunan

\section{KESIMPULAN DAN SARAN}

\section{Kesimpulan}


1. Sebelum diberikan terapi relaksasi pernafasan dalam, seluruhnya responden mengalami kecemasananak SD kelas 6 dalam menunggu hasil ujian nasional (UAN) di SDN-4 Kumpai Batu Bawah.

2. Sesudah diberikan terapi relaksasi pernafasan dalam, ternyata terjadi penurunan kecemasan pada responden yaitu hampir dari keseluruhan responden tidak mengalami kecemasananak SD kelas 6 dalam menunggu hasil ujian nasional (UAN) di SDN-4 Kumpai Batu Bawah.

3. Ada pengaruh terapi relaksasi pernafasan dalam terhadap penurunan kecemasan anak SD kelas 6 dalam menunggu hasil ujian nasional (UAN) di SDN-4 Kumpai Batu Bawah.

\section{Saran}

1. Bagi responden Siswa-siswi SDN4 Kumpai Batu Bawah.

Memberikan solusi penanganankecemasandengan terapi relaksasi pernafasan dalam. Agar dapat menangani kecemasan dengan terapi relaksasi pernapasan dalam, tanpa melakukan hal-hal negatif yang tidak diingikan, mengingat dampak buruk dan membahayakan keselamatan diri seseorang pada saat menunggu hasil ujian nasioanl (UAN).

2. Bagi sekolah SDN-4 Kumpai Batu Bawah.

Memberikan informasi kepada sekolah tentang terapi relaksasi pernapasan dalam terhadap penurunan kecemasan. Sehingga sebagai pertimbangan sekolah untuk meningkatkan ketenangan siswa-siswi dalam menunggu hasil ujian nasional.
3. Bagi peneliti selanjutnya.

Melakukanpenelitiantentang faktor lain yang berhubungan dengan terapi relaksasi nafas dalam terutama faktor yang mempengaruhi terapi seperti konsentrasi, situasi, keinginan dan lain-lain.

\section{DAFTAR PUSTAKA}

Arikunto. (2006). Prosedur penelitian : suatu pendekatan praktek. Jakarta: Rineka Cipta.

Hidayat, \& Alimun, A. A. (2010). Metode penelitian kesehatan paradigm kuantitatif. Surabaya: Health Books Publishing.

Hawari, D., 2011. Manajemen Stres Cemas dan Depresi. Jakarta : Balai Penerbit FKUILong, Barbara C, 1996,Perawatan Medikal Bedah, (Volume 2),Penerjemah: Karnaen, Adam, Olva, dkk, Bandung: Yayasan Alumni Pendidikan

Keperawatan

Hisam. (2016, November 7). Pendidikan. Retrieved Agustus 3, 2017, from dosenpendidikan.com:

Prasetyo. (2012, November 5). Hipertensi. Retrieved juli 3, 217, from analisi: http://www.lib.ui.ac.id/file?file =digital/20307703-T31185Analisis\%20faktor.pd

http://www.dosenpendidikan.com/13pengertian-siswa-menurut-paraahli-terlengkap/

Sugiyono, 2007. Metode penelitian pendidikan (pendekatan 
kuntitatif, kualitatif dan R\&D),

Alfabeta

Suliswati, (2005). Konsep Dasar

Keperawatan Kesehatan Jiwa.

Bandung: Alfabeta.

Taylor \& La Mone. (1997). Fundamentals of nursing: the art and science of nursing care B. Third Edition. Philadhelpia:

Lippincott 